\title{
Organização das ações em sistemas ofensivos no goalball
}

\section{RESUMO}

O goalball diferentemente de outros esportes paralímpicos foi criado exclusivamente para a pessoa com deficiência visual. Os estudos a respeito desse são relativamente escassos no que se refere a análise de sistema ofensivo de jogo. Nesse sentido, o objetivo desse ensaio foi apresentar modelos de sistemas de jogo ofensivo em que a estratégia e a tática se aplicam no goalball como meio facilitador da aprendizagem e de comunicação. A proposta foi padronizada de maneira ilustrativa e sistematizada, na qual as estruturas de posicionamento tático do goalball com foco nas estratégias de ataque possuem por finalidade a organização e qualidade técnica do jogo. O principal encaminhamento desse ensaio foi sistematizar estruturas que permitam o entendimento do atleta com deficiência visual através de estratégias que permitam a leitura das ações ofensiva de uma equipe de goalball.

PALAVRAS-CHAVE: Goalball; Tática; Sistemas ofensivos
Gabriel Goulart Siqueira

Especialista

Universidade Federal de Juiz de Fora, Departamento em Esportes e Atividades

Físicas Inclusivas para Pessoas com

Deficiência,

Juiz de Fora, Brasil

gabrielpolui@hotmail.com

https://orcid.org/0000-0003-0520-2114

Carolyne de Lima Saraiva

Graduada

Universidade Paulista, Departamento de

Educação Fisica Bacharel,

Brasilia, Brasil

carolsaraiv@hotmail.com

${ }^{\circ}$ https://orcid.org/0000-0001-7080-5718

Ciro Winckler

Doutor

Universidade Federal de São Paulo, Departamento de Ciências do Movimento

Humano

Santos, Brasil

ciro.winckler@unifesp.br

@https://orcid.org/0000-0002-9595-8144 


\title{
Organization of actions in offensive systems at goalball
}

\begin{abstract}
Goalball, unlike other Paralympic sports, was created exclusively for a person with visual impairment. Studies on these are relatively scarce when it comes to an analysis of the offensive game system. In this sense, the objective of this essay was to present models of offensive game systems in which strategy and tactics are applied in goalball as a means of facilitating learning and communication. The proposal was standardized in an illustrative and systematized manner, in which the structures of tactical positioning of goalball with a focus on attack strategies have, by size, the organization and technical quality of the game. The main purpose of the test was to structure the structure of the understanding of the visually impaired athlete through strategies that lead to the reading of the actions of a goalball team.
\end{abstract}

KEYWORDS: Goalball; Tactic; Offensive systems

\section{Organización de acciones en sistemas ofensivos en goalball}

\section{RESUMEN}

El goalball, a diferencia de otros deportes paralímpicos, fue creado exclusivamente para personas con discapacidad visual. Los estudios sobre esto son relativamente escasos cuando se trata del análisis del sistema de juego ofensivo. En este sentido, el objetivo de este ensayo fue presentar modelos de sistemas de juego ofensivos en los que se aplican estrategias y tácticas en el goalball como medio para facilitar el aprendizaje y la comunicación. La propuesta se estandarizó de manera ilustrativa y sistematizada, en la que las estructuras de posicionamiento táctico del goalball con enfoque en estrategias de ataque apuntan a la organización y calidad técnica del juego. El objetivo principal de este ensayo fue sistematizar estructuras que permitan la comprensión del atleta con discapacidad visual a través de estrategias que permitan la lectura de las acciones ofensivas de un equipo de goalball.

PALABRAS-CLAVE: Goalball; Táctica; Sistemas ofensivos 


\section{INTRODUÇÃO}

O Goalball é um esporte praticado exclusivamente por atletas cegos e com baixa visão. Foi criado em 1946 para contribuir na reabilitação de veteranos que perderam a visão durante a Segunda Guerra Mundial, sendo que o austríaco Hans Lorenzen e o alemão Sepp Reindle são creditados pela invenção do jogo (Comitê Paralímpico Brasileiro, 2020). Atualmente o esporte apresenta como um de seus principais objetivos sua prática em alta performance, sendo que esse tem evoluído de maneira muito rápida nos últimos ciclos paralímpicos.

A modalidade caracteriza-se por ser coletiva, na qual os comportamentos dos jogadores influenciam direta ou indiretamente no resultado do jogo. Uma destas características é a tomada de decisão no momento das ações defensivas e ofensivas (AMORIM, 2010). Para Morato e colaboradores (2007) as equipes se organizam ofensivamente e defensivamente conforme os sistemas táticos aplicados, concedendo funções a serem realizadas por cada jogador.

Nesse sentido, a tática é a capacidade baseada em processos cognitivos de recepção, transmissão, análise de informações, elaboração de resposta e execução da ação motora, concretizada pelo uso de uma técnica especifica, implicando na tomada de decisão, a qual reflete o nível de entendimento da tática e a experiência motora do atleta (FIGUEIRA; GREGO, 2008). Tendo em vista que é na ação do jogo que se justifica a importância do comportamento tático do jogador para o rendimento esportivo, sendo esse salientado num conjunto de métodos ou procedimentos de capacidades específicas que impactam numa organização situacional (FIGUEIRA; GREGO, 2008, p.55).

A análise técnico-tática realizada de forma rápida e precisa permitem as equipes instrumentos que possam encaminhar ao sucesso esportivo (MCGARRY, 2005), assim como a informação técnica traz a realidade dos fatos e auxiliam ao treinador na modificação da equipe da melhor maneira para ganhar um jogo (TRAPP, et al 2017).

A tática é representada pelas ações individuais e coletivas dos jogadores de uma equipe organizada e orientada por um plano de ações previamente estabelecido, esses visam solucionar as tarefas-problemas durante uma partida, considerando as características dos jogadores e sua função nas situações de ataque ou defesa (FIGUEIRA; GREGO, 2008). Nesse aspecto existe a necessidade de organização das ações ofensivas, que embora aleatórias no goalball, possibilita uma melhor comunicação entre treinador e atleta, além de proporcionar maior qualidade técnica ao jogo, evitando o ataque ineficaz frente à defesa e criando um cenário com melhor aproveitamento do tempo do ataque e maiores probabilidades de acertos. 
Considerando que a tática coletiva pressupõe a organização de toda a equipe para justificar e orientar a intenção tática individual de cada jogador (BAYER, 1994) é através da tática coletiva que cada jogador se torna encarregado de realizar uma função específica, ou seja, é a partir desse sistema organizado e orientado que possibilita a cada jogador o entendimento da ação específica a realizar (MORATO, 2007).

Nesse sentido, Nascimento e Camargo (2013) apresentam que o entendimento das variações táticas no goalball é a maneira pela qual os jogadores compreendem a dinâmica do sistema em jogo e permitem ações para reorganizá-las, podendo pensar e repensar os "sistemas de posicionamentos". Nesse processo a equipe tem instrumentos para definir suas estratégias de defesa e de ataque, mediante casualidades (p.e. placar empatado, derrota anunciada ou possibilidade de vitória). Com essa leitura, a equipe pode criar ações para ludibriar o adversário, realizando jogadas de efeito ou mesmo jogadas combinadas. Desse modo, toda ação individual e coletiva deverá ser conectada por uma técnica executada, inserida na situação de jogo (FIGUEIRA; GREGO, 2008).

No caso específico do atleta com deficiência visual, a sistematização pode ser ferramenta fundamental para potencializar a performance, tendo em vista que a ausência da leitura incidental feita pela visão leva a uma maior variabilidade de respostas (SONKSEN; DALE, 2002) evitando um maior gasto energético ou erro nas tomadas de decisão (WINCKLER; MIRANDA, 2018). A sistematização tática pode ser fundamental para solucionar essa condição, pois o como fazer (técnicas) aliado às razões do fazer (táticas) são elementos chaves para o entendimento do jogo (GARGANTA, 1995). Instrumentalizar a leitura técnico-tática, quer em treino, quer em competição, é um processo fundamental na avaliação e na otimização do desempenho, permitindo maximizar os processos de aprendizagem e introduzindo objetividade nas tomadas de decisão pelo atleta (FERREIRA, et al, 2020).

Diante disso, o objetivo desse ensaio foi apresentar a uma proposta de sistematização de modelos e estratégias de ataque no Goalball.

\section{Fundamentação teórica}

Sabe-se que para a aprendizagem motora, a informação visual é muito relevante. Para o cego essa será influenciada nas informações dos outros sentidos e o ato motor deverá desenvolver-se através de experiências vividas (CASTRO, 1993). Nesse sentido as estruturas do jogo deverão ser construídas respeitando essa entrada de informações sensoriais.

Morato (2012) afirma que para ajustar a lógica do jogo de goalball as equipes necessariamente deverão cumprir os princípios defensivos (balanço defensivo, leitura da trajetória, interceptação do arremesso) e ofensivos (controle de bola, preparação do ataque, efetivação do 
arremesso), além de utilizarem esse ciclo como referência para a auto-organização. No processo de auto-organização, caso a equipe seja eficiente no controle de bola e tenha bastante tempo, esta poderá combinar ações entre jogadores e alterar as origens de arremesso. Com isso, a equipe poderá surpreender e/ou desorganizar o balanço defensivo adversário.

Cada equipe terá quatro (4) tempos técnicos de 45 segundos durante a partida, é de direito dos técnicos dar instruções aos jogadores em quadra durante o tempo oficial do árbitro, mesmo estando o técnico na área do banco (SILVA, 2008). Nesse momento, o treinador tem a possibilidade de solicitar à sua equipe um determinado sistema ofensivo condizente conforme a falha encontrada na equipe adversária. A estrutura da quadra de jogo é um elemento invariante nessa organização. Essa apresenta formato retangular com dimensões de dezoito metros de comprimento por nove metros de largura. As balizas situam-se sobre as linhas de fundo da quadra e em toda a largura tendo 1,30 metro de altura. Cada metade da quadra é dividida em três áreas de dimensões idênticas (figura 01): área de defesa (ou de equipe), área de ataque (ou de lançamento) e área neutra, todas as marcações realizadas por linhas em relevo (MORATO, 2012).

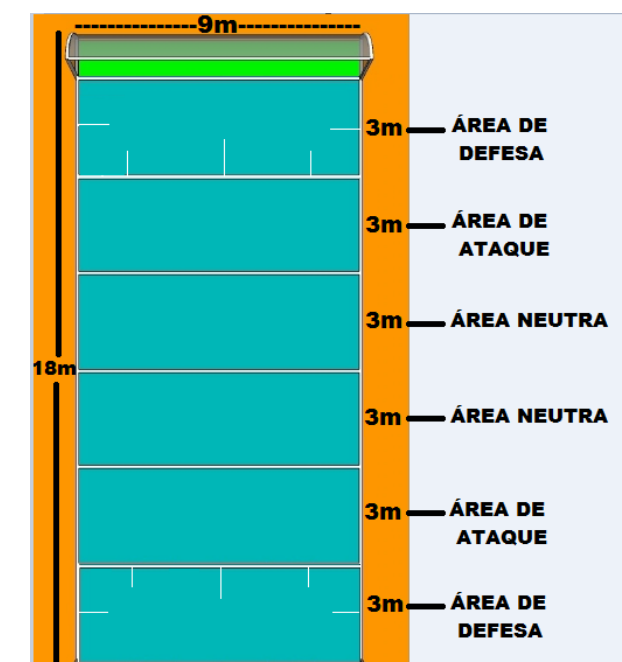

Figura 1 - Divisão ta quadra de goalball (Fonte: elaborado pelos autores)

O cego tem que recorrer a outros sentidos para poder deslocar-se de maneira segura e interagir com o ambiente (CASTRO, 1993). No goalball, devido à ausência da leitura incidental do ambiente através da visão, os jogadores utilizam os sentidos remanescentes para se deslocar e retornar à sua origem com segurança, fazendo o uso das linhas em alto-relevo, a baliza ou até mesmo os próprios membros da equipe como referências. Para Mendonça et al (2008) a visão integra todos os estímulos que recebemos através dos outros sentidos.

A área de defesa é o principal ponto de referência para a orientação espacial dos jogadores. Nessa existem diferentes marcações diferenciando-as das demais marcações que passam a ser referências para as posições dos jogadores (ala esquerdo, ala direito e central) (MORATO, 2012). 
O tempo de jogo e suas divisões são outro aspecto que ajustam as ações. As partidas são disputadas em dois tempos de doze minutos, com três minutos de intervalo entre esses. Caso uma equipe abra dez gols de vantagem sobre o adversário, a partida é encerrada, independente do tempo regulamentar restante (MORATO, 2012). Cada ação de ataque deverá ocorrer em no máximo 10 segundos pela equipe com a posse de bola, além do que cada equipe terá direito a quatro (4) tempos técnicos de 45 segundos durante toda a partida (IBSA, 2020). Essa condição temporal apresenta um cenário em que as tomadas de decisões devem ocorrer em um período curto e o treinador possui poucas oportunidades para instruir a equipe, desse modo a utilização da sistematização do ataque poderá auxiliar na comunicação entre treinador e atleta.

Para o atleta com deficiência visual a dinâmica do jogo baseia-se nas percepções auditivas, táteis e orientação espacial. Permitindo a esses perceberem as linhas em alto-relevo que compõe a quadra, e localizam a bola por meio do barulho dos guizos que possui (MAGALHAES, 2015).

Esse sistema de informações deverá ser usado para gerar a organização tática. Essa segundo Hainaut e Benoit (1979 apud COSTA et al., 2009) ocorre conforme os jogadores entendem seus deslocamentos, bem como, limites e posições de origem da bola em relação aos seus companheiros ou adversários. Portanto, a utilização das técnicas corretas no sistema ofensivo pode definir um resultado positivo, permitindo atacar a defesa adversária em um alvo desejado, desestruturar a defesa com o intuito de marcar gol ou alcançar um determinado nível de desempenho ofensivo como, por exemplo, variar o ritmo de jogo.

O posicionamento dos jogadores em quadra de acordo com a função exercida por cada um é denominado de sistema tático (BALBINO, 2001; BAYER, 1994; BOTA; COLIBABA-EVULET, 2001; SANTANA, 2004; SOUZA, 1999). Para Morato et al. (2007) tal posicionamento está diretamente ligado às ações dos adversários e as equipes tendem a alterar seu sistema tático durante o jogo de acordo com a ineficiência no sistema utilizado pelo adversário.

Pensando em criar referências para organizar o posicionamento dos atletas e facilitar a leitura das ações técnicas, frente a limitação de informações incidentais nos atletas de goalball, Morato et al. (2018), propuseram uma caracterização da quadra que permite avaliação das trajetórias e o tempo de bola tanto pelos atletas quanto aos treinadores. Desse modo a quadra foi dividida em seis setores de 1,5 metros de largura. Esses setores permitem desse modo melhorar o nível de rendimento de origem e alvo dos arremessos.

A figura 2 apresenta que a quadra da equipe de defesa seja representada nos setores de origem, enquanto os setores de alvo serão representados na quadra adversária (MORATO, 2012). 


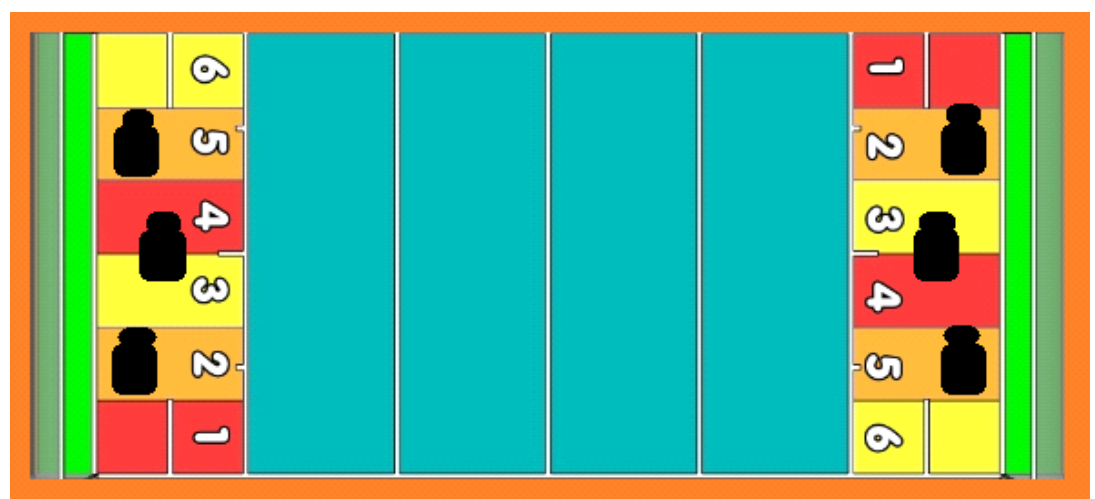

Figura 2 - sistematização de origem e alvo (Fonte: elaborado pelos autores).

Essa estruturação permite aos jogadores, aquilo que Garganta e Pinto (1994), definem como um conjunto de regulações sobre o jogo que possibilita rapidamente soluções táticas para os problemas provenientes da situação que defrontam. Devido ao atleta com deficiência visual ter uma limitação na construção do mapa espacial do jogo pela ausência visual esta demanda informações diferenciadas e sistematizadas para elaborar um mapa cognitivo e gerar as possibilidades de ação. Segundo Mendonça et al. (2008) para a construção do mapa cognitivo, torna-se fundamental a existência de uma aprendizagem e treino dos conceitos espaciais por meio da criação de experiências concretas como condições para uma boa orientação espacial e conseguinte deslocação independente.

De acordo com Tosim et al. (2008) para uma equipe ter resultados satisfatórios é preciso que os atletas possuam não só uma boa técnica, mas também uma boa tática, que pode ser delineada como maneira de se organizar e aplicar sua técnica de maneira eficiente. No goalball, os atletas constroem a imagem mental do time adversário e dos alvos a fim de obter maior precisão técnica e tática. Para Roqué e Rosaneli (2018), a construção de uma imagem mental é composta por uma gama de elementos perceptivos a partir dos sentidos, não apenas a partir da informação visual de uma cena ou objeto, e no caso do atleta com deficiência visual seus sentidos remanescentes elaboram imagens mentais que formam a experiência do lugar.

Para García (2000), um dos parâmetros essenciais na organização do jogo coletivo ofensivo de alto rendimento é a variação das ações de ataque. Nesse sentido, uma equipe com seu sistema ofensivo bem estruturado e variado é fundamental para que se obtenha um bom desempenho. Para isso, possibilitar a vivência dessas condições permite tomadas de decisões mais consistentes, mediante a situação exigida (MELO et al., 2007). No goalball por ser uma modalidade bastante dinâmica, permitir informações que contribuam para o aprendizado incidental e que possibilitem a construção de uma estratégia ofensiva pode mudar o resultado da partida e por esse motivo a importância de se analisar e organizar os sistemas ofensivos. 
Projetar uma estrutura de ataque, na qual a equipe alcance alta eficiência é, sem dúvida, uma das tarefas mais complexas enfrentadas pelo treinador. A estruturação do ataque permite que os jogadores se organizem para coordenar suas ações individuais e coletivas na busca pelo objetivo principal do jogo ofensivo: conseguir o gol (GARCÍA; GARCÍA; ANOZ, 2004). Este ensaio organiza as ações ofensivas por meio de sistemas táticos com o intuito de auxiliar a comunicação entre treinador e atleta com deficiência visual evitando que o atleta realize um ataque aleatório e desperdice arremessos, a partir da construção dos mapas mentais.

\section{ELABORAÇÃO DO SISTEMA OFENSIVO}

O estudo de Fujita, Furtado e Morato (2021) apresenta que a maioria dos arremessos têm arremessos com origem nas laterais da quadra, ou seja, são os arremessos mais eficientes, sendo os diagonais de origem 1 para alvo 3, origem 5 para alvo 3. Esses resultados de eficiência reforçam o padrão solicitado pelos treinadores em busca das falhas na defesa. Para Morato (2012) o ataque sempre busca o "buraco" que é o espaço entre os alas e o central. Essa condição impacta que o os atletas cheguem na bola com as extremidades do corpo (mão e pé), no jogo essa situação se chama quina, pois apresentam maiores dificuldades de bloquear os arremessos se comparadas ao bloquear a bola com tronco e quadril.

O desenvolvimento de um sistema ofensivo, de acordo com Morato (2012), permite que a jogada combinada possa ser definida como ações pré-estabelecidas com movimentações conjuntas (envolvendo mais de um jogador) com a intenção de confundir o balanço defensivo e a leitura de jogo do adversário. Tendo em vista que a leitura de jogo pelo atleta no goalball ocorre através da percepção auditiva, pois combinar essas estruturas pré-definidas permitem uma maior eficiência da tática de jogo.

A utilização de cada sistema ofensivo no jogo está ligada às características ofensivas dos atletas ou ao sistema defensivo utilizado pela equipe adversária. Permitindo que os jogadores se organizem em diferentes movimentações e posições, mesmo com informações incidentais mais limitadas como no caso da audição. A seguir, estão descritos alguns sistemas de ataque e suas principais características visando organizar ações sistematizadas.

\section{SISTEMA OFENSIVO CONE ABERTO}


- Objetivo: Atacar os alvos extremos do campo adversário isolando o central.

- Pontos de origem: 3 ou 4.

- Alvos: 1 e 2 ou 5 e 6.

Neste sistema a comunicação entre os atletas é muito importante, pois os três atletas podem realizar o arremesso da posição central. No caso de um dos alas realizar essa ação o central terá que se deslocar, liberando a área de origem dos arremessos para que os atletas não se choquem. Devido a origem da bola ser na área central, o primeiro som da bola em contato com o solo poderá fazer com que a defesa adversária busque mais a parte central da quadra, abrindo buracos nas extremidades, onde será o alvo do arremesso. Podendo assim ser visualizada na forma da figura de um cone aberto a partir das possibilidades de trajetória da bola, como consta na Figura 3.

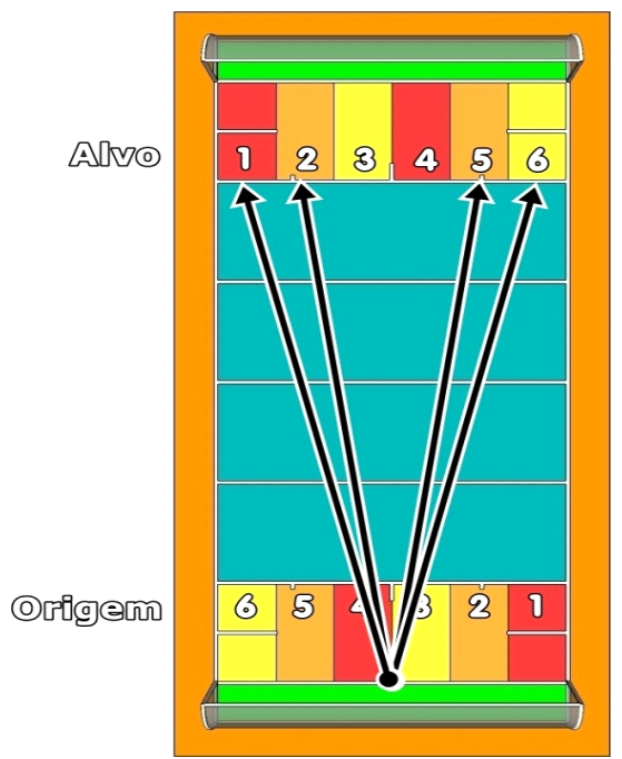

Figura 3 - Sistema Ofensivo Cone Aberto (Fonte: elaborado pelos autores).

Legenda: Setas pretas arremessos diagonais com origem no centro e alvo nas regiões laterais da quadra $(1,2,5,6)$

\section{SISTEMA OFENSIVO CONE FECHADO}

- Objetivo: Atacar o centro da baliza do adversário.

- Pontos de origem: 1 e 2 ou 5 e 6

- Alvos: 3 e 4.

Neste sistema o maior volume de bolas arremessadas vai para à área central. Devido a isso, os atletas tendem a se deslocarem fechando mais para os pontos 2 e 3 , e 4 e 5 , o que pode ocasionar uma abertura nos pontos 1 e 6, como consta na Figura 4. 


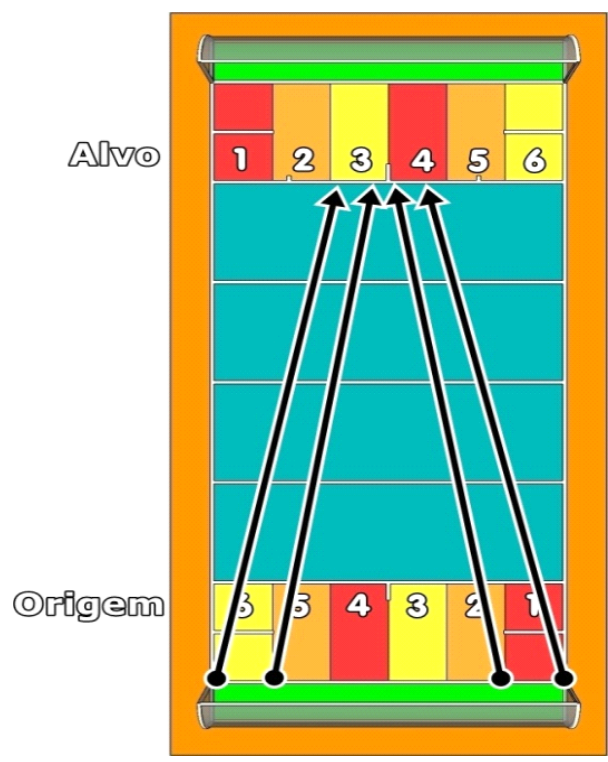

Figura 4 - Sistema ofensivo cone fechado (Fonte: elaborado pelos autores).

Legenda: setas pretas arremessos diagonais com origem nas laterais e alvo nas regiões centrais da quadra $(3,4)$

\section{SISTEMA OFENSIVO ESPELHO}

- Objetivo: Atacar os alvos à sua frente.

- Pontos de origem: $6,5,4,3,2$ ou 1 .

- Alvos: 1, 2, 3, 4, 5 ou 6 .

Neste sistema o atleta que for realizar a ação ofensiva se posicionará na origem de frente para o alvo, sendo assim, se o atleta for atacar o alvo 6, sua origem será o ponto 1 , cf. a figura 5 .

A eficiência desse arremesso está associada com a característica da trajetória da bola, que pode ser uma bola rápida quicada ou rente ao solo com trajetória paralela fazendo com que essa chegue o mais rápido possível no alvo desejado. 


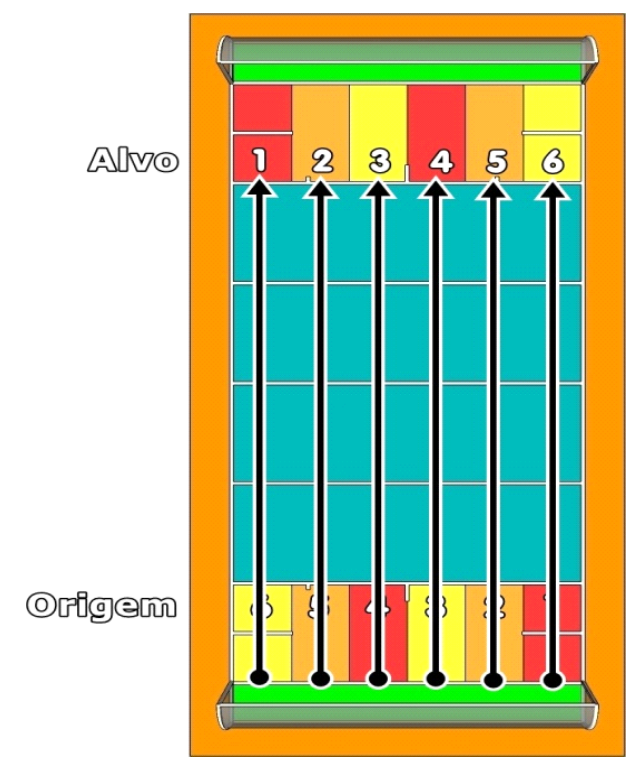

Figura 5 - Sistema ofensivo espelho (Fonte: elaborado pelos autores).

Legenda: Setas pretas: arremessos paralelos

\section{SISTEMA OFENSIVO ARRASTA}

- Objetivo: Deslocar o central para uma extremidade e ocasionar a abertura de um possível "buraco".

- Pontos de origem: 3 e 5 .

- Alvos: 3 e 4 ou 4 e 5 .

Este sistema ofensivo tem como função concentrar um maior volume de bola entre os pontos 3 e 4 ou 4 e 5 com intuito de deslocar/arrastar o central mais para a direita ou esquerda. Podendo assim, desorganizar o retorno do central para a sua origem, deixando uma possível abertura, um "buraco", em uma das extremidades, conforme a figura 6. 


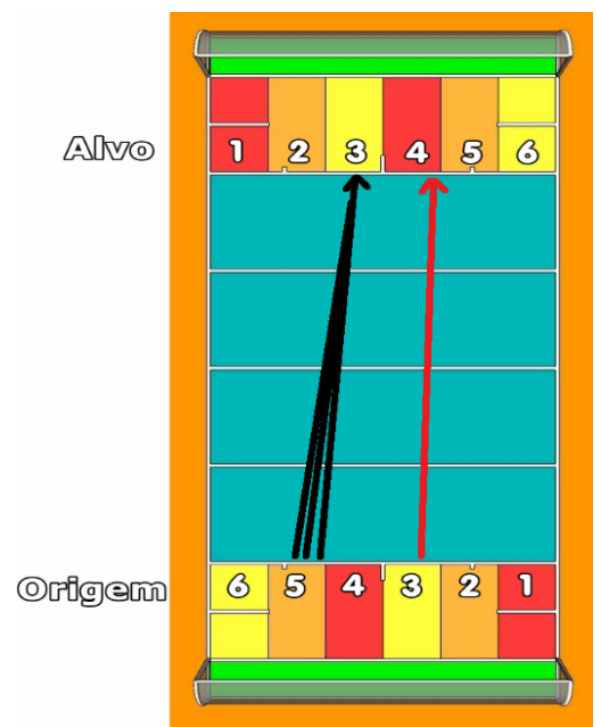

Figura 6 - Sistema ofensivo arrasta (Fonte: elaborado pelos autores).

Legenda: Setas pretas: arremessos consecutivos no mesmo alvo; seta vermelha: arremesso na abertura do possível desequilíbrio defensivo

\section{SISTEMA OFENSIVO DIAGONAL DIREITA}

- Objetivo: Atacar o adversário com bolas na diagonal.

- Pontos de origem: 6,5 ou 4.

- Alvos:4, 5 ou 6.

Neste sistema os arremessos têm origem apenas do lado esquerdo da quadra havendo flutuações somente do ala direito, no qual o atleta se deslocará do seu setor para as origens 4,5 ou 6 para realizar o ataque. As bolas arremessadas devem ter o trajeto em diagonal. Como consta na figura 7.

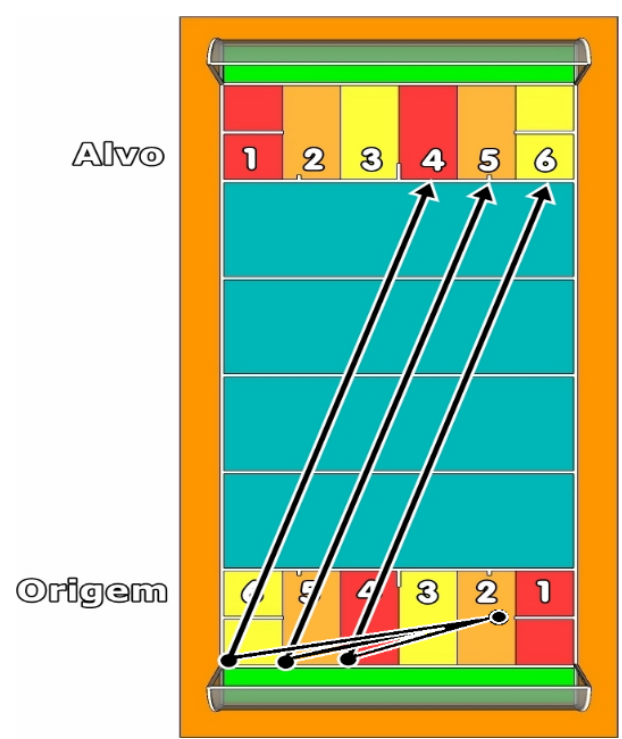

Figura 7 - Sistema ofensivo diagonal direita (Fonte: elaborado pelos autores). 


\section{SISTEMA OFENSIVO DIAGONAL ESQUERDA}

- Objetivo: Atacar o adversário com bolas na diagonal.

- Pontos de origem: 3,2 ou 1.

- Alvos: 1, 2 ou 3.

Neste sistema os arremessos têm origem apenas do lado direito da quadra havendo flutuações somente do ala esquerdo, no qual este se deslocará do seu setor para as origens 3,2 ou 1 para realizar o ataque. As bolas arremessadas devem ter o trajeto em diagonal. De acordo com a figura 8 .

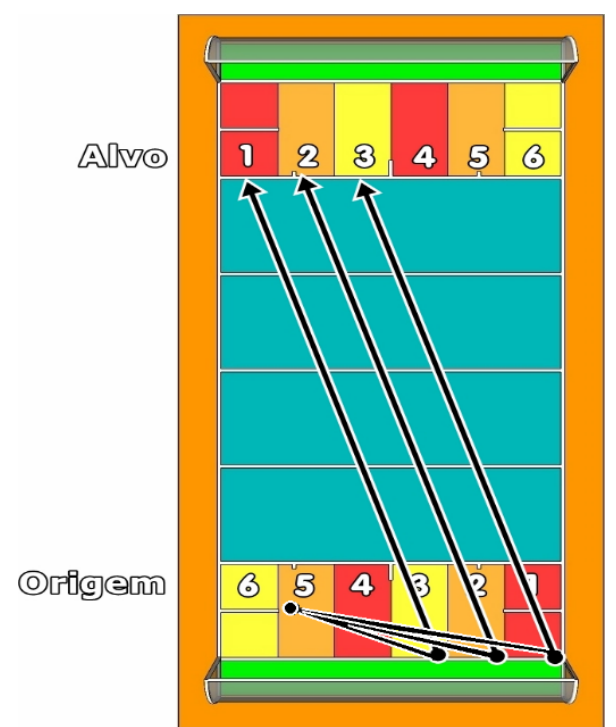

Figura 8 - Sistema ofensivo diagonal esquerda (Fonte: elaborado pelos autores).

Legenda: Setas pretas: deslocamento dos atletas com arremessos na diagonal

\section{SISTEMA OFENSIVO "X"}

- Objetivo: Confundir a defesa adversária com constantes flutuações dos alas.

- Pontos de origem: $6,5,4,3,2$ ou 1

- Alvos: 1, 2, 3, 4, 5 ou 6 .

Neste sistema os alas direito e esquerdo fazem constantes flutuações cruzando os arremessos com o intuito de confundir a defesa adversária com o barulho que é realizado durante os deslocamentos. O ala esquerdo desloca (flutuação) para a origem 1, 2 ou 3 e arremessa nos alvos 1, 2 ou 3, e o ala direito desloca (flutuação) para a origem 4,5 ou 6 e arremessa nos alvos 4,5 ou 6 . É importante que os atletas tenham uma boa noção espacial, pois sua corrida em direção a ala oposta tem como objetivo confundir a defesa do adversário, e o retorno para sua origem deve ser rápido para não haver o risco de levar um gol de contra-ataque. De acordo com a figura 9. 


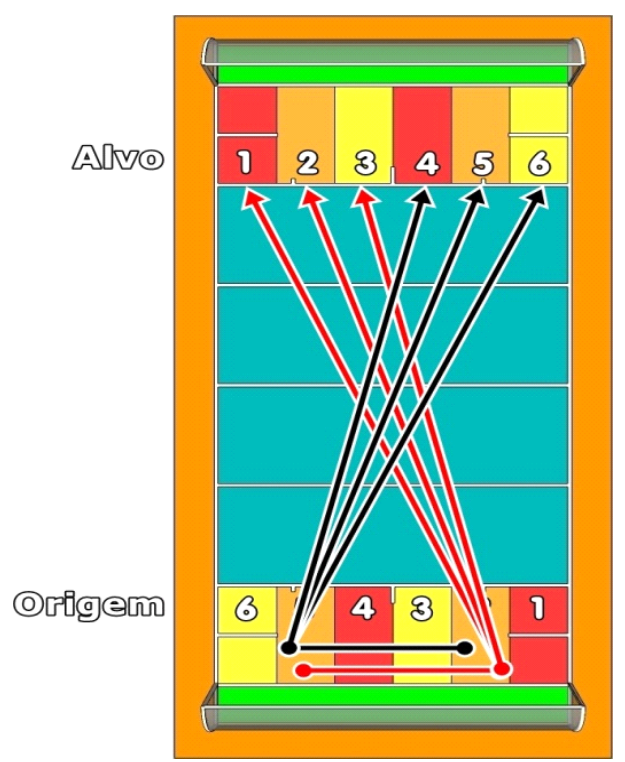

Figura 9 - Sistema ofensivo X (Fonte: elaborado pelos autores).

\section{SISTEMA OFENSIVO DE BLOCO DIREITO}

- Objetivo: Atacar o adversário somente do lado direito da quadra.

- Pontos de origem: 3,2 ou 1.

- Alvos: 4,5 ou 6 .

Neste sistema o ataque é realizado exclusivamente do lado direito da quadra atingindo somente os alvos 4, 5 ou 6. Esse sistema é utilizado quando é identificado que o lado esquerdo da defesa é o mais vulnerável da equipe adversária ou quando se tem a intenção de poupar a posse de bola do ala direito, se este for um atleta de maior poder defensivo e ou ofensivo. Conforme a figura 10.

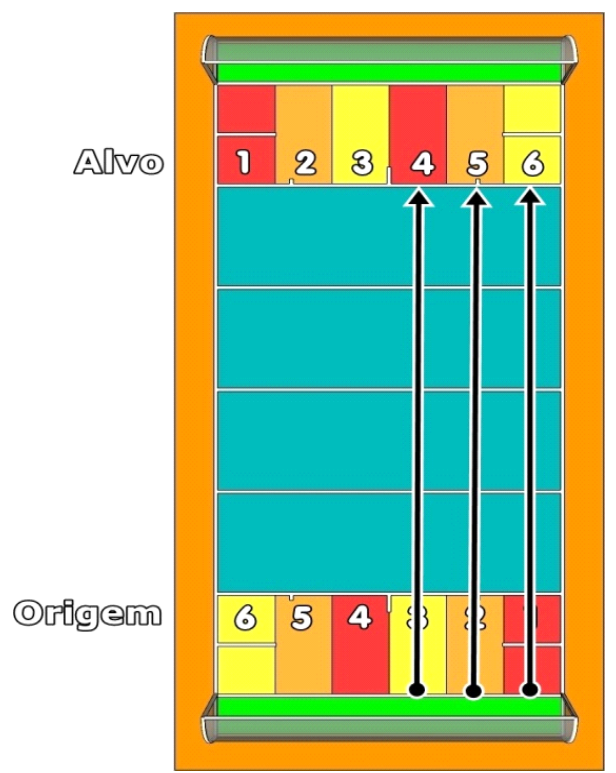

Figura 10 - Sistema ofensivo de bloco direito (Fonte: elaborado pelos autores). 


\section{SISTEMA OFENSIVO DE BLOCO ESQUERDO}

- Objetivo: Atacar o adversário somente do lado esquerdo da quadra.

- Pontos de origem: 6, 5 ou 4 .

- Alvos: 1,2 ou 3.

Neste sistema o ataque é realizado exclusivamente do lado esquerdo da quadra atingindo somente os alvos1, 2 ou 3. Este sistema é utilizado quando é identificado que o lado direito da defesa é o mais vulnerável da equipe adversária ou quando se tem a intenção de poupar a posse de bola do ala esquerdo, se este for um atleta de maior poder defensivo e ou ofensivo. De acordo com a figura 11 .

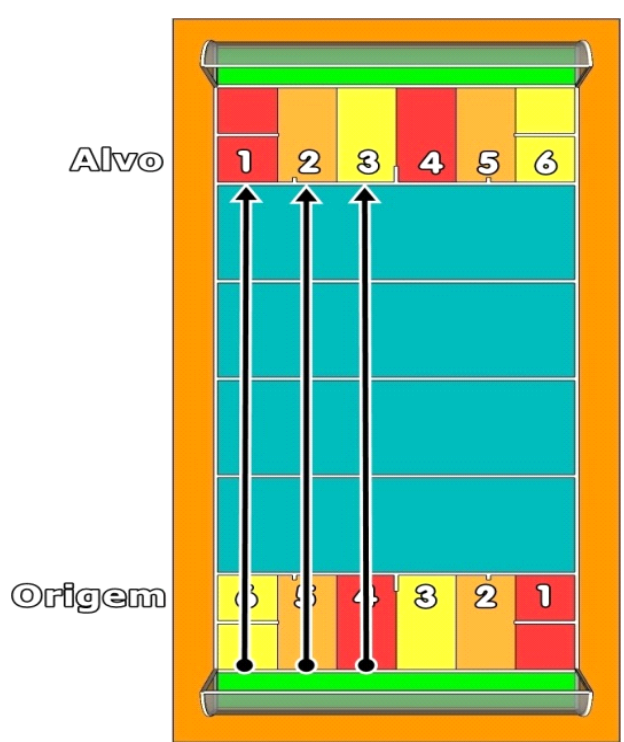

Figura 11 - Sistema ofensivo de bloco esquerdo (Fonte: elaborado pelos autores).

Legenda: Setas pretas: arremessos na paralela na esquerda

\section{Conclusão}

Os apontamentos desse ensaio mostram que entendem que para obter conexão, efetividade e equilíbrio funcional nas ações ofensivas os atletas devem apresentar alto entendimento tático com objetivo de não desagregar a consistência do time, podendo assim jogar como um todo insolúvel.

$\mathrm{Na}$ aprendizagem da tática para o atleta com deficiência visual é importante estimular a leitura ambiental pelo tato e a audição, associando essa às estruturas de leitura ou aos movimentos padronizados que permitem uma maior eficiência na resposta. Como estratégia pessoal de ensino, o treinamento repetitivo de ações de aprimoramento (a contagem de passos, a presença de barulhos 
externos à quadra para melhor concentração ao som da bola e da movimentação adversária, as marcações da quadra e as emendas da baliza) auxiliam o atleta a uma melhor ambientação ao espaço de jogo, o que consequentemente refletirá em uma tática ofensiva eficiente.

A padronização permite não apenas criar uma metodologia para o treinamento de ações, mas permite aos atletas com deficiência visual, um maior conhecimento das posições em quadra e das funções técnicas. Outro ponto relevante é que permite a criação de subsídios para uma boa comunicação durante o jogo.

Esses sistemas ofensivos podem ser aplicados quando o técnico localiza alvos mais frágeis no sistema defensivo adversário e solicita aos atletas o sistema ofensivo condizente com as estratégias de ataque nas falhas adversária. Mesmo o sistema solicitado estando definido e claro permite ao time um elevado nível de criatividade na movimentação sincrônica e coordenada. Este ensaio demonstrou maneiras de organização das ações ofensivas, ações que pretendem facilitar a aprendizagem do atleta e a comunicação entre técnico-atleta tendo por finalidade organização e qualidade técnica do jogo através da utilização dos sistemas ofensivos.

\section{REFERÊNCIAS}

AMORIM, Minerva. Plasticidade comportamental no deficiente visual: estudo com deficientes visuais em tarefas específicas do Goalball. Dissertação (Doutorado em Ciência do Desporto) - Universidade do Porto, Porto, 2010. Disponível em: https://repositorio -aberto.up.pt/bitstream/10216/26006/2/23187.pdf. Acesso em: 23 de Mai. 2020.

BALBINO, Hermes Ferreira. Jogos desportivos coletivos e os estímulos das inteligências múltiplas. Dissertação (Mestrado em Educação Física) - Universidade Estadual de Campinas, Campinas, 2001. Disponível em: http://repositorio.unicamp.br/bitstream/REPOSIP/275462/1/Balbino_HermesFerreira_M.pdf. Acesso em: 23 de Mai. 2020.

BAYER, Claude. O ensino dos desportos coletivos. Lisboa: Dinalivro, 1994.

BOTA, Ioan; COLIBABA-EVULET, Dumitru. Jogos desportivos coletivos: teoria e metodologia. Lisboa, Instituto Piaget, 2001.

Comitê Paralímpico Brasileiro. Goalball. Disponível em: http://www.cpb.org.br/portfolio/goalball/. Acesso em: 23 de Mai. 2020.

CASTRO, José Alberto Barbosa de Moura. Estudo da influência da capacidade de resistência aeróbia na orientação e mobilidade do cego. Dissertação (Ciência do Desporto) - Universidade do Porto, Faculdade de Ciências do Desporto e de Educação Física, [Portugal], 1993. Disponível em: https://repositorioaberto.up.pt/bitstream/10216/10235/2/460_TD_01_C.pdf. Acesso em: 19 de Abr. 2020.

COSTA, Israel Teoldo da; GRECO, Juan Pablo; SILVA, Julio Manuel Garganta da; MESQUTA, Isabel. Tactical Principles of Soccer Game: concepts and application. Motriz. Journal of Physical Education, vol. 15, n. 3, p. 657-668, 2009. Disponível em: https://www.periodicos.rc.biblioteca.unesp.br/index.php/motriz/article/view/2488. Acesso em: 08 de Fev. 2020.

DO NASCIMENTO, Dailton Freitas; DE CAMARGO, Wagner Xavier. Sequenciando fundamentos táticos do goalball para professores-técnicos de educação física adaptada: os sistemas de defesa. Cadernos de Formação 
RBCE, vol.3, n.2, 2013. Disponível em: http://revista.cbce.org.br/index.php/cadernos/article/view/1380/830. Acesso em: 19 de Abr. 2020.

FERREIRA, Márcia Daniela Faria; SANTOS, Joao Alberto Valente dos. Observação e análise técnico-tática da eficácia ofensiva no goalball. Dissertação (Mestrado em Treino Desportivo) - Universidade Lusófona de Humanidades e Tecnologias, Lisboa, 2020. Disponível em: http://hdl.handle.net/10437/11502. Acesso em: 13 de Abr. 2021.

FIGUEIRA, Fabrício Moreira; GRECO, Pablo Juan. Futebol: um estudo sobre a capacidade tática no processo de ensino-aprendizagem-treinamento. Revista Brasileira de Futebol, vol. 1, n. 2, p. 53-65, 2008. Disponível em: https://rbf.ufv.br/index.php/RBFutebol/article/view/34. Acesso em: 14 de Abr. 2021.

FUJITA Rafael; FURTADO Otávio; MORATO Márcio. Ball trajectories and the probability of scoring a goal in elite male goalball throws. European Journal of Adapted Physical Activity, vol. 14, n. 1, 2021. Disponível em: https://eujapa.upol.cz/pdfs/euj/2021/01/07.pdf. Acesso em: 02 de Mai. 2021.

GARCÍA CALVO, Tomas; GARCÍA HERRERO, Juan; ANOZ LEGARRA, Ignacio. Análisis de la estructura del ataque en equipos de alto nivel de balonmano. Apunts: Educación física y deportes, vol. 76, p. 53-58, 2004.

GARCÍA, Juan Antonio. La estructuración del juego de ataque en la etapa de perfeccionamiento. Curso de Actualización en Balonmano. Instituto Andaluz del Deporte. Cádiz, 2000. Não paginado.

GARGAnTA, Júlio. Para uma Teoria dos Jogos Desportivos Coletivos. In: GRAÇA, Amândio; OLIVEIRA, José (Eds.). O ensino dos jogos desportivos. 2. ed. Porto: Universidade do Porto, 1995. Não paginado.

GARGANTA, Julio; PINTO, Jorge. O ensino do futebol. In: GRAÇA, A. OLIVEIRA, J. (Ed.). O ensino dos jogos desportivos. Porto: Faculdade de Ciências do Desporto e de Educação Física da Universidade do Porto: Rainho \& Neves. vol. 1, p. 95-136, 1994.

INTERNATIONAL BLIND SPORTS FEDERATION, IBSA IBSA Goalball Rules and Regulations 20182021. Disponível em: https://ibsasport.org/wp-content/uploads/2020/07/182-1-IBSA-Classification-rules-2018.pdf. Acesso em: 26 de Jun. 2020.

MAGALHAES, Thiago Pinguelli. Análise cinemática das ações ofensivas no goalball em situação de jogo: deslocamento do jogador e arremesso. Dissertação (Mestrado em Ciências da Nutrição e do Esporte e Metabolismo) Universidade Estadual de Campinas, Faculdade de Ciências Aplicadas, Limeira, 2015. Disponível em: http://repositorio.unicamp.br/bitstream/REPOSIP/244496/1/Magalhaes_ThiagoPinguelli_M.pdf. Acesso em: 20 de Abr. 2021.

MCGARRY, Tim; FRANKS, Ian. The science of match analysis. In T. Reilly \& M. Williams (Eds.), Science and Soccer (Second Edition ed., p. 265-275). New York: Routledge.

2005. Disponível em: https://www.taylorfrancis.com/chapters/edit/10.4324/9780203417553-24/science-match-analysistim-mcgarry-ian-franks. Acesso em: 15 de Abr. 2021.

MELO, Vitor Paulo de; PAOLI, Próspero Brum; SILVA, Cristiano Diniz da. O desenvolvimento do processo de treinamento das ações táticas ofensivas no futebol na categoria infantil. Lecturas Educación Física y Deportes. Revista Digital. Buenos Aires, vol. 11, n. 104, 2007. Disponível em: https:/www.efdeportes.com/efd104/treinamentodas-acoes-taticas-ofensivas-no-futebol.htm. Acesso em: 20 de Abr. 2021.

MENDONÇA, Alberto; CRISTINA, Miguel; NEVES, Graça; MICAELO, Manuela; REINO, Vitor. Alunos cegos e com baixa visão. Orientações curriculares. Lisboa: Dgidc. 2008. P.73. Disponível em https://www.dge.mec.pt/sites/default/files/EEspecial/publ_alunos_cegos.pdf. Acesso em: 20 de Abr. 2020.

MORATO, Márcio Pereira; MENEZES, Rafael Pombo; FONSECA, Sofia; FURTADO, Otavio Luis Paiva da Cunha. Faster balls increase the probability of scoring a goal in female and male elite goalball. Revista Brasileira de Ciências do Esporte, vol. 40, n. 4, p. 427-434, 2018. Disponível em:

https://www.scielo.br/scielo.php?script=sci_arttext\&pid=S0101-32892018000400427. Acesso em: 20 de Dez. 2020.

MORATO, Marcio Pereira. Futebol para cegos (futebol de cinco) no Brasil: leitura do jogo e estratégias táticotécnicas. Dissertação (Mestrado em Educação Física) - Universidade Estadual de Campinas, Faculdade de Educação 
Física, Campinas, 2007. Disponível em: http://repositorio.unicamp.br/jspui/handle/REPOSIP/275176. Acesso em: 20 de Dez. 2020.

MORATO, Marcio Pereira. Análise do jogo de goalball: modelação e interpretação dos padrões de jogo da Paraolimpíada de Pequim 2008. Tese (Doutorado) - Universidade Estadual de Campinas, Faculdade de Educação Física, Campinas, 2012. Disponível em: http://repositorio.unicamp.br/handle/REPOSIP/275036. Acesso em: 22 de Dez. 2020.

ROQUÉ, Bianca Beatriz; ROSANELI, Alessandro Filla. Imagens mentais de pessoas cegas: a percepção ambiental na geografia fenomenológica. Geograficidade, vol. 8, n. 2, p. 95-107, 2018. Disponível em: https://dialnet.unirioja.es/servlet/articulo?codigo=7339390. Acesso em: 19 de Abr. 2020.

SANTANA, Wilton Carlos de. Futsal: apontamentos pedagógicos na iniciação e na especialização. Autores Associados, Campinas, 2004.

SILVA, Gilberto Carlos Pereira da. Tempo de reação do jogador de goalball na interceptação/defesa do lançamento/ataque. Dissertação (Mestrado em Educação Física)-Universidade Estadual de Maringá, Centro de Ciências da Saúde, Maringá, 2008 Disponível em: http://repositorio.uem.br:8080/jspui/handle/1/2245. Acesso em: 20 de Abr. 2021.

SONKSEN, Patricia; DALE, Naomi.

Visual impairment in infancy: impact on neurodevelopmental and neurobiological processes. Developmental Medicine \& Child Neurology, vol. 44. p. 782-791, 2002. Disponível em:

https://search.proquest.com/openview/99ffa3421318903e166b7c0547494766/1?pqorigsite=gscholar\&cbl=34809.

Acesso em: 20 de Dez. 2020.

SOUZA, Pablo Castagnino. Proposta de avaliação e metodologia para desenvolvimento do conhecimento tático em esportes coletivos: a exemplo do futsal. In: BRASIL I Prêmio INDESP de literatura esportiva,vol. 1, Brasília, 1999.

TOSIM, Alessandro; JUNIOR, Alaercio Perotti; LEITAO, Maria Teresa K; ; SIMOES, Regina. Sistemas técnicos e táticos no goalball. Revista Mackenzie de Educação Física e Esporte, vol. 7, n. 2, p. 146, 2008. Disponível em: http://www.deficienciavisual.pt/txt-sistemas_tecnicos_tacticos_Goalball-Tosim_Perotti_Leitao_Simoes.htm. Acesso em: 19 de Abr. 2020.

TRAPP, Altemir; RUDEK, Marcelo; CANCIGLIERI, Osiris; ZANETTI, Roberto. Development of a Specialized System for Goalball's Game Tactical Analysis. 7th International Conference on Information Society and Technology ICIST. 2017. Disponível em: http://www.eventiotic.com/eventiotic/files/Papers/URL/5474ca1f-01d9-473e-9b223d6c923fbaaf.pdf. Acesso em: 15 de Abr. 2021.

WINCKLER, Ciro; MIRANDA, Andrea Jacusiel. The Athlete with Visual Impairment. Aspetar Sports Medicine Journal. vol. 7, n. 17, p. 138-141, 2018. Disponível em: https://www.aspetar.com/journal/viewarticle.aspx?id=431. Acesso em: 19 de Abr. 2020.

\section{NOTAS DE AUTOR}

\section{AGRADECIMENTOS}

Gostaríamos de agradecer primeiramente a Deus, aos professores, atletas e familiares que contribuíram com a realização do manuscrito.

CONTRIBUIÇÃO DE AUTORIA - Não se aplica

FINANCIAMENTO - Não se aplica.

CONSENTIMENTO DE USO DE IMAGEM - Não se aplica 
APROVAÇÃO DE COMITÊ DE ÉTICA EM PESQUISA - Não se aplica.

\section{CONFLITO DE INTERESSES}

Os autores não apresentam conflito de interesse em relação ao material publicado

\section{LICENÇA DE USO}

Os autores cedem à Motrivivência - ISSN 2175-8042 os direitos exclusivos de primeira publicação, com o trabalho simultaneamente licenciado sob a Licença Creative Commons Attribution Non-Comercial ShareAlike (CC BY-NC SA) 4.0 International. Esta licença permite que terceiros remixem, adaptem e criem a partir do trabalho publicado, desde que para fins não comerciais, atribuindo o devido crédito de autoria e publicação inicial neste periódico desde que adotem a mesma licença, compartilhar igual. Os autores têm autorização para assumir contratos adicionais separadamente, para distribuição não exclusiva da versão do trabalho publicada neste periódico (ex.: publicar em repositório institucional, em site pessoal, publicar uma tradução, ou como capítulo de livro), com reconhecimento de autoria e publicação inicial neste periódico, desde que para fins não comerciais e compartilhar com a mesma licença.

\section{PUBLISHER}

Universidade Federal de Santa Catarina. Programa de Pós-Graduação em Educação Física. LaboMídia - Laboratório e Observatório da Mídia Esportiva. Publicado no Portal de Periódicos UFSC. As ideias expressadas neste artigo são de responsabilidade de seus autores, não representando, necessariamente, a opinião dos editores ou da universidade.

\section{EDITORES}

Mauricio Roberto da Silva, Giovani De Lorenzi Pires, Rogério Santos Pereira.

\section{EDITOR DE SEÇÃO}

Giovani De Lorenzi Pires

\section{REVISÃO DO MANUSCRITO E METADADOS}

João Caetano Prates Rocha; Keli Barreto.

\section{HISTÓRICO}

Recebido em: 27 de fevereiro de 2021.

Aprovado em: 17 de maio de 2021. 